\title{
BMJ Open Prevalence of disabilities and non- communicable diseases in an elderly population in the Telangana state, India: a population-based cross-sectional study
}

\author{
Srinivas Marmamula (D) , ${ }^{1,2,3,4}$ Satya Brahmanandam Modepalli, ${ }^{1}$ \\ Thirupathi Reddy Kumbham, ${ }^{1}$ Rajesh Challa, ${ }^{1}$ Jill E Keeffe ${ }^{1}$
}

To cite: Marmamula S, Modepalli SB, Kumbham TR, et al. Prevalence of disabilities and non-communicable diseases in an elderly population in the Telangana state, India: a population-based crosssectional study. BMJ Open 2021;11:e041755. doi:10.1136/ bmjopen-2020-041755

- Prepublication history for this paper is available online. To view these files, please visit the journal online (http://dx.doi. org/10.1136/bmjopen-2020041755).

Received 17 June 2020 Revised 30 December 2020 Accepted 21 January 2021

Check for updates

(C) Author(s) (or their employer(s)) 2021. Re-use permitted under CC BY-NC. No commercial re-use. See rights and permissions. Published by BMJ.

For numbered affiliations see end of article.

Correspondence to Dr Srinivas Marmamula; sri.marmamula@lvpei.org

\section{ABSTRACT}

Objectives To assess the prevalence of disabilities (vision, hearing, mobility, cognitive, self-care and communication) and non-communicable diseases (NCDs) among the elderly population in two districts in Telangana, India. Design Population-based cross-sectional study using a cluster random sampling method to select the study clusters.

Setting Elderly population in Khammam and Warangal districts were recruited. Detailed interviews were conducted by trained community health workers. Personal and demographic information such as age, gender, level of education and a self-report of NCDs was collected. The Washington Disability Questionnaire was administered to assess the presence of disabilities.

Participants 1821 participants aged $\geq 60$ years, $54.5 \%$ were women, and $73.3 \%$ had no education.

Primary outcome measure Prevalence of disabilities and NCDs.

Results Overall, the prevalence of at least disability was $20.3 \%$ (95\% Cl 16.3 to 24.9). The prevalence of selfreported disabilities were: seeing $(5.9 \% ; 95 \% \mathrm{Cl} 4.4$ to $7.8)$, mobility (12.8\%; $95 \% \mathrm{Cl} 9.7$ to 16.8$)$, hearing (3.6\%; $95 \% \mathrm{Cl} 2.7$ to 4.8$)$, cognition (4.8\%; 95\% Cl 3.5 to 6.7$)$, self-care $(3.3 \%$; $95 \% \mathrm{Cl} 2.3$ to 4.7$)$ and communication (1.8\%; $95 \% \mathrm{Cl} 1.2$ to 2.6). Overall, the prevalence of at least one NCD was $34.2 \%$ (95\% Cl 30.9 to 37.7$)$. Hypertension was the most common systemic condition (25.4\%; $95 \% \mathrm{Cl} 22.4$ to 28.7 ), followed by diabetes $(9.0 \%$; $95 \% \mathrm{Cl} 7.3$ to 11.0 ), and body pains (muscle-skeletal) (9.9\%; $95 \% \mathrm{Cl} 8.1$ to 12.2$)$.

Conclusion Every fifth elderly person in the districts of Khammam and Warangal in Telangana had at least one self-reported disability. Besides, a third of the elderly had at least one NCD. There is a definite need to develop comprehensive public health strategies to address disabilities and NCDs in Telangana.

\section{INTRODUCTION}

According to the WHO estimates, $15 \%$ of the global population is disabled. ${ }^{1}$ In the 2011 census, the prevalence of disability was reported as $5.1 \%$ in the elderly population in India. ${ }^{2}$ It had a higher prevalence in rural areas and older age groups. ${ }^{2}$ Movement and
Strengths and limitations of this study

- Provided insights on the prevalence of disabilities and non-communicable diseases in the elderly population in two districts where recent data are not available.

- Successfully used rapid assessment method designed for eye health to assess the prevalence of disabilities and non-communicable diseases in the population.

- As a low-cost rapid assessment study method was used, it will be possible to repeat the study at regular intervals to assess the temporal trends over time.

- Disabilities were assessed using 'self-report' using the Washington Disability Questionnaire.

- The data from this study can be used for healthcare planning in the state.

vision impairment individually accounted for $25 \%$ of total disabilities followed by disabilityrelated to hearing which was $19 \%$. $^{2}$ However, the more recent paper compared the census estimates with the prevalence found in household-level surveys and found a significant variation in the prevalence estimates of the disabilities using these two approaches. ${ }^{3}$ People with disabilities are vulnerable and face several attitudinal, physical and financial barriers to access healthcare. ${ }^{4}$

Globally, non-communicable diseases (NCDs) are a cause of death in over 41.5 million and contributes to over $73 \%$ of the mortality. ${ }^{5}$ Over half of the population in the older age group suffer from at least one chronic condition in India. ${ }^{6}$ NCDs are common among the elderly as reported from the first wave of the WHO Study on global AGEing (SAGE) studies conducted in India during 2007-2010. ${ }^{6}$ A more recent study revealed that about $44 \%$ of older individuals have at least one NCD. ${ }^{7}$ Hypertension, diabetes and heart disease are seen in $14 \%$, 
$9 \%$ and $8.1 \%$, respectively in India. ${ }^{8}$ One-third of those aged 50 years and older had hypertension in India in the SAGE study. ${ }^{9}$

Disabilities and NCDs are more common in the elderly (60 years and older) population in India. ${ }^{2} 6910$ These adversely affect the quality of their lives and lead to an increase in medical care needed. As per the 2011 census, the elderly constituted $8.2 \%$ of the population of India. However, the proportion of elderly is expected to increase to $20 \%$ by the year $2050 .{ }^{11}$ With this increase in the proportion of the elderly in India, the number of people having disabilities and NCDs is also expected to rise.

Population-based epidemiological data are vital for planning healthcare and rehabilitation strategies to address NCDs and disabilities. Regional studies provide information that can be used for district-level planning. Rapid assessment methods have been used commonly in the domain of eye health for over the last two decades. ${ }^{12}$ As these methods can be applied using limited resources in a short time, they are used as tools for planning and monitoring of eye care services. ${ }^{12}$ Over 300 rapid assessment studies were conducted world over in the last two decades and they form an important element in estimating the global burden of vision loss. ${ }^{13}$ There has been a recommendation to include the assessment of disabilities in these rapid assessment studies. ${ }^{13}$ We included the assessment of disabilities and NCDs in our rapid assessment study conducted in two large districts in the state of Telangana in India.

The state of Telangana in South India was separated from Andhra Pradesh as the new 29th state of India in 2014. This newly formed state comprises 10 districts and has a population of 35.2 million people as per the 2011 census. The total population of the two districts Khammam and Warangal is estimated at 6.3 million. About $10 \%$ of the population is estimated to be in the elderly age group. This research aimed to determine the prevalence of self-reported disabilities and NCDs such as hypertension, diabetes and heart disease in the elderly population in two large districts in the south Indian state of Telangana.

\section{METHODS}

The Washington Group developed a short set of questions for use in censuses and population surveys to provide comparable data across studies and regions. ${ }^{14} 15$

The study protocol was piggy-backed on a populationbased cross-sectional study that was conducted to assess the burden of visual impairment using the Rapid Assessment of Visual Impairment (RAVI) methodology. ${ }^{16-18}$ The study protocol, sampling method and the results have been reported in our previous publications. ${ }^{16-18}$ In brief, a multi-stage cluster random methodology was used to select the study clusters. The compact segment sampling method was used to enlist the households in each cluster. In each study cluster, 50 people were enumerated and all those who were available were recruited. Detailed interviews were conducted by trained community health workers. Personal and demographic information such as age, gender, level of education (years of education) and a self-report of NCDs (diabetes, hypertension and heart disease) and current medication for these conditions were recorded.

From the Washington Disability Questionnaire (WDQ) the following questions regarding disabilities were asked in the local language (Telugu): (1) do you have difficulty seeing, even if wearing glasses? (2) do you have difficulty hearing, even if using a hearing aid? (3) do you have difficulty walking or climbing steps? (4) do you have difficulty remembering or concentrating? (5) do you have difficulty (with self-care such as) washing all over or dressing? (6) using your usual (customary) language, do you have difficulty communicating, for example, understanding or being understood? Each of these questions had four options based on severity, such as (1) not at all (2) some difficulty (3) a lot difficulty and (4) cannot do at all. Based on responses of the subjects, 'not at all' and 'some difficulty' were considered as no disability, and 'a lot difficulty' and 'cannot do at all' were considered as having a disability.

\section{Data management}

Data were analysed using the design-based analysis to account for the cluster sampling design using sampling weights. The statistical significance was assessed at the conventional level of $\mathrm{p}$ value less than 0.05 (two-tailed). Design based, multiple logistic regression was used to assess the association between disabilities and NCDs and other sociodemographic variables. The adjusted OR with 95\% CIs were presented. A similar analysis was also done for any NCDs. Data analysis was conducted using Stata Statistical Software for Windows, V.14 (StataCorp).

\section{Patient and public involvement}

Patients and other members of the public were not involved in the study.

\section{RESULTS}

\section{Demographic characteristics}

Overall, 5357 people aged 40 years and older were examined as a part of the RAVI study. ${ }^{16-18}$ This cohort included 1958 elderly participants of whom 1821 (93\%) responded to the WDQ and the systemic health questionnaire. Of the 1821 participants, $54.5 \%$ ( $\mathrm{n}=993$ ) were women, $73.3 \%$ $(n=1335)$ had no education and $42.6 \%(n=776)$ were from Khammam district. The mean age of the participants was 68.7 years (SD: 7.1 years; range: $60-102$ years) (table 1 ).

\section{Disability}

Overall, the prevalence of disability was $20.3 \%$ (95\% CI 16.3 to 24.9 ). In terms of the number of disabilities, $12.1 \%$ reported one disability, $5.6 \%$ reported two disabilities and $2.7 \%$ reported three or more disabilities. The prevalence 
Table 1 Characteristics of the study sample and the prevalence of disabilities and non-communicable diseases

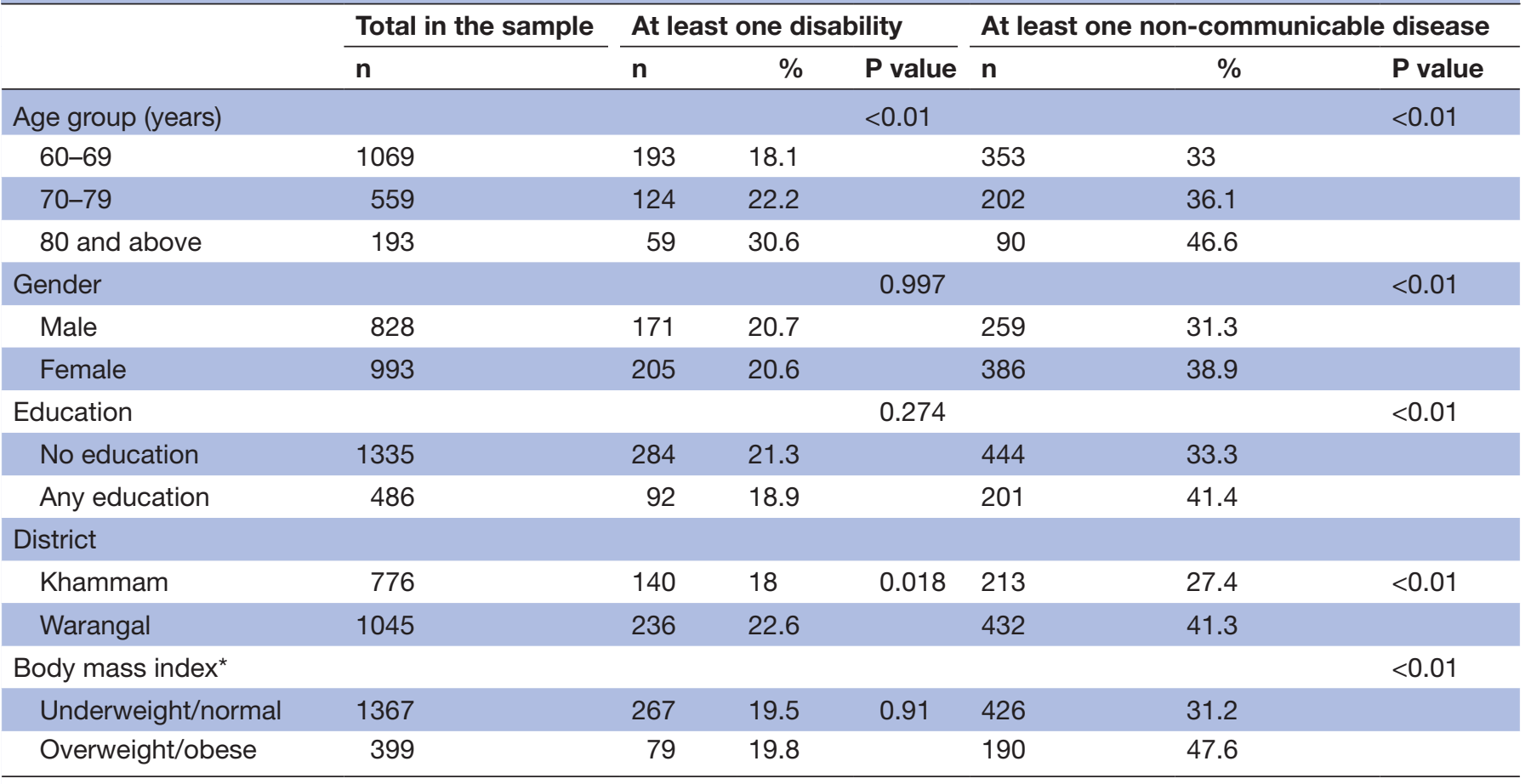

*Data not available on 55 participants.

of self-reported disabilities was: seeing $(5.9 \%$; $95 \%$ CI 4.4 to 7.8$)$, mobility $(12.8 \%$; $95 \%$ CI 9.7 to 16.8$)$, hearing $(3.6 \% ; 95 \%$ CI 2.7 to 4.8$)$, cognition $(4.8 \%$; $95 \%$ CI 3.5 to $6.7)$, self-care $(3.3 \% ; 95 \%$ CI 2.3 to 4.7$)$ and communication $(1.8 \%$; $95 \%$ CI 1.2 to 2.6$)$ (table 2$)$.

On multivariable analysis, the odds for disability were higher among 80 years and older age group (OR: 1.62; $95 \%$ CI 1.07 to 2.46). Gender, education level, district of residence and body mass index (BMI) were not associated with disability. Those with at least one NCD had a higher odds for disability (OR: $1.40 ; 95 \%$ CI 1.07 to 1.83 ) (table 3).

\section{Non-communicable diseases}

Overall, the prevalence of at least one NCD was $34.2 \%$ (95\% CI 30.9 to 37.7 ). In terms of the number of NCDs,

\begin{tabular}{lc}
\hline \multicolumn{2}{l}{ Table 2 Prevalence of disabilities } \\
\hline \multicolumn{2}{l}{ Prevalence $(95 \%$ Cl) } \\
\hline Washington disability categories \\
WDQ1 - seeing & $5.9(4.4$ to 7.8$)$ \\
WDQ2 - hearing & $3.6(2.7$ to 4.8$)$ \\
WDQ3 - mobility & $12.8(9.7$ to 16.8$)$ \\
WDQ4 - cognition & $4.8(3.5$ to 6.7$)$ \\
WDQ5 - self-care & $3.3(2.3$ to 4.7$)$ \\
WDQ6 - communication & $1.8(1.1$ to 2.6$)$ \\
At least one disability & $20.3(16.3$ to 24.9$)$
\end{tabular}

WDQ, Washington Disability Questionnaire.
$27.0 \%$ reported one $\mathrm{NCD}, 6.7 \%$ reported two conditions and $0.5 \%$ had reported three or more conditions. Hypertension was the most common systemic condition (25.4\%; $95 \%$ CI 22.4 to 28.7$)$, followed by diabetes $(9.0 \%$; $95 \%$ CI 7.3 to 11.0 ), and body pains (muscle-skeletal) $(9.9 \%$; $95 \%$ CI 8.1 to 12.2$)$ (table 4$)$. In total, $33.8 \%$ of the participants using at least one medication for their NCDs.

On multivariable analysis, the presence of at least one systemic condition was associated with oldest age groups (OR: $1.80 ; 95 \%$ CI 1.26 to 2.56), female gender (OR: 1.62; $95 \%$ CI 1.32 to 1.98 ), any education (OR: 1.76 ; $95 \%$ CI 1.31 to 2.37 ) and among those elderly living in Warangal (OR: $1.91 ; 95 \%$ CI 1.38 to 2.65 ). The elderly who were overweight/obese had higher odds for NCD (OR: 1.89; $95 \%$ CI 1.45 to 2.46 ) compared with those with normal BMI or underweight. Those with at least one disability had higher odds for NCD (OR: $1.40 ; 95 \%$ CI 1.07 to 1.83 ) (table 5).

\section{DISCUSSION}

Every fifth elderly person in the districts of Khammam and Warangal in Telangana has at least one self-reported disability. As found in earlier studies including the 2011 census, mobility was the most common disability in the elderly population. ${ }^{2}$ After poor mobility, vision impairment was the most common disability reported by the elderly participants. As vision plays an important role in our daily life, the impact of vision disability would be substantial. Some studies have reported on the impact of vision loss on quality of life and visual functioning in the 
Table 3 Effect of age, gender, education status and the district of residence on the prevalence of any disability (multiple logistic regression analysis)

\begin{tabular}{|c|c|c|c|}
\hline & Adjusted OR & $95 \% \mathrm{Cl}$ & $P$ value \\
\hline \multicolumn{4}{|l|}{ Age group (years) } \\
\hline $60-69$ & Reference & & \\
\hline $70-79$ & 1.26 & 0.95 to 1.68 & 0.06 \\
\hline 80 and above & 1.62 & 1.07 to 2.46 & 0.02 \\
\hline \multicolumn{4}{|l|}{ Gender } \\
\hline Male & Reference & & \\
\hline Female & 0.92 & 0.72 to 1.17 & 0.5 \\
\hline \multicolumn{4}{|l|}{ Education } \\
\hline No education & Reference & & \\
\hline Any education & 0.87 & 0.59 to 1.27 & 0.47 \\
\hline \multicolumn{4}{|l|}{ District } \\
\hline Khammam & Reference & & \\
\hline Warangal & 1.28 & 0.71 to 2.28 & 0.4 \\
\hline \multicolumn{4}{|l|}{$\mathrm{BMI}$} \\
\hline $\begin{array}{l}\text { Underweight/ } \\
\text { normal }\end{array}$ & Reference & & \\
\hline $\begin{array}{l}\text { Overweight/ } \\
\text { obese }\end{array}$ & 1.01 & 0.71 to 1.41 & 0.97 \\
\hline \multicolumn{4}{|l|}{ At least one NCD } \\
\hline No & Reference & & \\
\hline Yes & 1.4 & 1.07 to 1.83 & 0.01 \\
\hline
\end{tabular}

BMI, body mass index; NCD, non-communicable disease.

elderly. ${ }^{19-21}$ The prevalence of disability among elderly people has varied significantly across the studies in India. It ranges from $16.2 \%$ in West Bengal, ${ }^{22} 20.6 \%$ in Tamil $\mathrm{Nadu}, 57 \%$ in Karnataka, ${ }^{23} 67.1 \%$ in Maharashtra ${ }^{24}$ and $87.5 \%$ in Haryana and Chandigarh..$^{25}$ A large regional variation in the prevalence of disability is reported from Uttar Pradesh where it ranged from $23.4 \%^{26}$ to $53.6 \%{ }^{27}$ and from $20.6 \%$ to $68 \%$ in Tamil Nadu. ${ }^{28}$

Table 4 Prevalence of Non-Communicable Diseases (NCDs)

Prevalence $(95 \% \mathrm{Cl})$

\begin{tabular}{lc|}
\hline Non-communicable diseases & \\
\hline Hypertension & $25.4(22.4$ to 28.7$)$ \\
\hline Diabetes & $9.0(7.3$ to 11.0$)$ \\
\hline Heart disease & $1.5(0.9$ to 2.4$)$ \\
\hline Gastric problem & $2.2(1.6$ to 3.1$)$ \\
\hline Asthma & $3.3(2.2$ to 4.7$)$ \\
\hline Thyroid issue & $0.9(0.5$ to 1.4$)$ \\
\hline Musculoskeletal pains & $9.9(8.1$ to 12.0$)$ \\
\hline At least one NCD & $35.4(30.9$ to 37.7$)$ \\
\hline
\end{tabular}

Table 5 Effect of age, gender, education status and the district of residence on the prevalence of non-communicable diseases (multiple logistic regression analysis)

\begin{tabular}{|c|c|c|c|}
\hline & Adjusted OR & $95 \% \mathrm{Cl}$ & $P$ value \\
\hline \multicolumn{4}{|l|}{ Age group (years) } \\
\hline $60-69$ & Reference & & \\
\hline $70-79$ & 1.19 & 0.94 to 1.52 & 0.18 \\
\hline 80 and above & 1.80 & 1.26 to 2.56 & $<0.01$ \\
\hline \multicolumn{4}{|l|}{ Gender } \\
\hline Male & Reference & & \\
\hline Female & 1.62 & 1.32 to 1.97 & $<0.01$ \\
\hline \multicolumn{4}{|l|}{ Education } \\
\hline No education & Reference & & \\
\hline Any education & 1.76 & 1.31 to 2.37 & $<0.01$ \\
\hline \multicolumn{4}{|l|}{ District } \\
\hline Khammam & Reference & & \\
\hline Warangal & 1.91 & 1.38 to 2.65 & $<0.01$ \\
\hline \multicolumn{4}{|l|}{ BMI } \\
\hline Underweight/normal & Reference & & \\
\hline Overweight/obese & 1.89 & 1.45 to 2.47 & $<0.01$ \\
\hline \multicolumn{4}{|l|}{ At least one disability } \\
\hline No & Reference & & \\
\hline Yes & 1.4 & 1.07 to 1.83 & $<0.01$ \\
\hline
\end{tabular}

BMI, body mass index.

Venkatorao et al found vision disability to be higher followed by mobility in rural Tamil Nadu..$^{28}$ Another study from the same state reported that $57 \%$ of the elderly had a vision disability followed by joint pains and stiffness in $43.4 \%$ of the subjects. ${ }^{8}$ The same study reported that hypertension, diabetes and heart disease were reported by $14 \%, 9 \%$ and $8.1 \%$, respectively. ${ }^{8}$ However, due to varying methods adopted by these studies, the direct comparison of the prevalence estimates across the studies is not possible. ${ }^{3}$

One out of every three elderly people in rural Telangana has at least one self-reported NCD. Hypertension is by far the most commonly reported health condition with every fourth elderly person affected by this condition followed by body pains (musculoskeletal) and diabetes. The high prevalence of mobility disability with a high prevalence of hypertension and diabetes pose serious challenges to healthcare providers. Both these NCDs similar to other non-communicable conditions need continuity of care. Availability of care as close as possible and as accessible as possible remain the main challenges that need to be overcome to address them.

We found a higher prevalence of NCDs in those who had any education while there was no statistically significant difference in the prevalence of disabilities. Those who are educated are more likely to seek healthcare and likely to get the diagnosis of NCDs and report it. Researchers 
have reported a large difference in objective assessment and self-report of NCDs such as hypertension. ${ }^{29}$ We also found that NCDs are more common in the Warangal district as compared with Khammam. This difference can be attributed to variability in healthcare availability and uptake in these districts. We have reported a higher prevalence of vision impairment in Warangal compared with Khammam district. ${ }^{16}$

Researchers have taken different approaches to understand disability which include the Barthel index for Instrumental Activities of Daily Living, the ICF (International Classification of Functioning, Disability and Health) framework $^{3031}$ and the Rapid Assessment of Disability questionnaire. ${ }^{32}$ Authors have also used the WHOQOL ${ }^{33}$ and Short Form $36 .{ }^{34}$ To address the constraints of our resources and to assess the burden of disability rapidly as a part of the larger eye health study, we used the WDQ approach as it was the most feasible option.

The present study was nested in a population-based study using the RAVI methodology to include disabilities and NCDs. ${ }^{16} 17$ As the prevalence of disabilities is higher than the prevalence of visual impairment, the sample size was adequate to study disabilities. We recommend that the WDQ can be added to rapid assessment studies such as RAVI and the Rapid Assessment of Avoidable Blindness (RAAB) as it provides valuable insights on disabilities and provides a more comprehensive overview of the healthcare situation in the region. This recommendation was also made by earlier eye health researchers. ${ }^{13}$ The questionnaire is simple and can be administered by community workers after a short training session. We also included a question on visual hallucinations which is a characteristic feature of Charles Bonnet Syndrome and published its prevalence for the first time in this population. ${ }^{18}$ Also, NCDs such as diabetes and hypertension are closely related to eye health which makes it relevant for eye researchers and eye health planners to include selfreporting of NCDs and disabilities in eye health studies.

We used a population-representative sample and hence the results from our study can be extrapolated to the population in this region. The combined population of the two districts is 6.3 million which is about $5 \%$ of the state. Hence, we believe our results can be extrapolated to the state of Telangana. We believe more and more vision impairment surveys will include the assessment of disabilities and NCDs in their studies. By extrapolating our data to the entire elderly population of about 3.6 million in Telangana, it is estimated that at least 0.73 million elderly are likely to have at least one disability and over 1.23 million elderly may have at least one NCD.

As highlighted in a review article by Ramadass et al there are no standard methods of accessing disability, quality of life and activity limitations. ${ }^{35}$ This impedes comparison across the studies. Definitions of other variables and analysis paradigm also add to the complexity. There is a definite need to use standard protocols to assess and report disabilities in community studies. There are some classic examples in the area of eye health where standard methods were adopted for assessing the prevalence and causes of vision loss. These low-cost rapid assessment methods (RAAB and RAVI) provide data that are directly comparable across regions and also across different timeperiods to assess the trends. ${ }^{12} 3637$

\section{Strengths and limitations}

The novelty of our study lies in the application of the disability questionnaire and NCDs questionnaire in a rapid assessment study. To our knowledge, ours is the first RAVI study in India to combine these questionnaires. The use of cluster random sampling methodology and the good response rate covering two large districts, are the strengths of our study. The self-report and questionnairebased assessment of disability and NCDs instead of actual measurement remains the limitation of our study as routine health examinations are not common among rural elderly residents. For example, vision loss by selfreport is likely to be much lower than that found in prevalence studies where actual visual acuity is measured. It is possible that only those with severe vision loss report 'unable to see' as a disability. The self-report is likely to be an underestimate of the actual prevalence. Despite this limitation, our study has provided valuable estimates of disability and systemic health situation in the two districts in Telangana in India which can be used by healthcare planners as a framework to provide rehabilitation and services in this region.

\section{CONCLUSION}

Elderly-friendly infrastructure and transportation facilities that take into cognizance the prevalent disabilities in the elderly especially mobility and vision loss, are relevant given the exponential rise in the elderly population in India. The overarching goal of 'Healthy Aging is Happy Aging' can be achieved only with a comprehensive public health approach. We reported a large burden of vision loss in the elderly in residential care in urban and rural locations in India. ${ }^{38}$ Due to changing trends in living arrangements among the elderly, the number of homes for the aged is likely to increase in the coming years. Hence the health policy for the elderly should be comprehensive in terms of coverage and should also include people living in homes for the aged. Having ramps at public places, seating with an armrest and hand railings wherever possible, can be of immense help for the elderly with disabilities. People with disabilities face several challenges to access healthcare and this can adversely impact the management of NCDs such as hypertension and diabetes and can lead to unfavourable outcomes. ${ }^{40}$ A checklist for the elderly-friendly healthcare facilities is validated and published. ${ }^{41}$ The Government of India launched National Programme for Health Care of the Elderly in 2010 intending to create a new healthcare framework for the elderly to provide accessible, affordable and comprehensive care to them. ${ }^{42}$ This also includes pension support for the elderly. The National Health Policy 2017 also aims for 
universal and affordable healthcare for all. ${ }^{43} 44$ However, much still needs to be done on the ground to realise the full potential of these initiatives. ${ }^{4}$ There is a definite need for a comprehensive elderly centric holistic health programmes including strengthening of primary healthcare to achieve the goal of universal health coverage and healthy ageing in elderly in India.

\section{Author affiliations}

${ }^{1}$ Allen Foster Community Eye Health Research Centre, Gullapalli Pratibha Rao International Centre for Advancement of Rural Eye care, L V Prasad Eye Institute, Hyderabad, India

${ }^{2}$ Brien Holden Institute of Optometry and Vision Science, L V Prasad Eye Institute, Hyderabad, India

${ }^{3}$ School of Optometry \& Vision Science, University of New South Wales, Sydney, New South Wales, Australia

${ }^{4}$ Wellcome Trust /DBT India Alliance fellow, L V Prasad Eye Institute, Hyderabad, India

Acknowledgements The authors thank the volunteers for their participation in the study and acknowledge Mr Vijay Kumar (administrator) for providing logistic support for the study. Ratnakar Yellapragada is acknowledged for his support in data management. The authors also thank Ms Neha Hassija and Dr Shobha Mocherla for their language inputs on earlier versions of our manuscript.

Contributors SM conceived the idea, designed and conducted the study, analysed the data, and wrote the manuscript. SBM, TRK and RC assisted in data collection, clinical quality control and supervised the field activities. JEK reviewed earlier versions of the manuscript and provided intellectual inputs. All authors have reviewed the final version of the manuscript.

Funding This work was supported by Hyderabad Eye Research Foundation (HERF), India; and Lions Clubs International Foundation-SightFirst Research grant (Grant No. SF-1943/UND).

Competing interests None declared.

Patient consent for publication Not required.

Ethics approval The study protocol was approved by the Institutional Review Board (IRB) of the Hyderabad Eye Research Foundation, L V Prasad Eye Institute, Hyderabad, India and it adhered to the tenets of the Declaration of Helsinki. Written informed consent was obtained from each participant before using the short set of the Washington Disability Questionnaire (WDQ).

Provenance and peer review Not commissioned; externally peer reviewed.

Data availability statement Data are available upon reasonable request.

Open access This is an open access article distributed in accordance with the Creative Commons Attribution Non Commercial (CC BY-NC 4.0) license, which permits others to distribute, remix, adapt, build upon this work non-commercially, and license their derivative works on different terms, provided the original work is properly cited, appropriate credit is given, any changes made indicated, and the use is non-commercial. See: http://creativecommons.org/licenses/by-nc/4.0/.

ORCID iD

Srinivas Marmamula http://orcid.org/0000-0003-1716-9809

\section{REFERENCES}

1 WHO. World report of diability 2011, 2011. Available: https://www. who.int/disabilities/world_report/2011/report.pdf; [Accessed 26 Mar 2020].

2 Velayutham B, Kangusamy B, Joshua V, et al. The prevalence of disability in elderly in India - Analysis of 2011 census data. Disabil Health J 2016;9:584-92

3 Dandona R, Pandey A, George S. India's disability estimates: limitations and way forward, 2019.

4 Gudlavalleti MVS, John N, Allagh K, et al. Access to health care and employment status of people with disabilities in South India, the side (South India disability evidence) study. BMC Public Health 2014;14:1125.

5 GBD 2017 Causes of Death Collaborators. Global, regional, and national age-sex-specific mortality for 282 causes of death in 195 countries and territories, 1980-2017: a systematic analysis for the global burden of disease study 2017. Lancet 2018;392:1736-88.

6 Arokiasamy PKowal P, et al. Chronic noncommunicable diseases in 6 low- and middle-income countries: findings from wave 1 of the world Health organization's study on global ageing and adult health (SAGE). Am J Epidemiol 2017;185:414-28.

7 Patel SA, Dhillon PK, Kondal D, et al. Chronic disease concordance within Indian households: a cross-sectional study. PLoS Med 2017; 14:e1002395.

8 Purty AJ, Bazroy J, Kar M. Morbidity pattern among the elderly population in the rural area of Tamil Nadu, India. Turkish J Med Sci 2006;36:45-50.

9 Wu F, Guo Y, Chatterji S, et al. Common risk factors for chronic non-communicable diseases among older adults in China, Ghana, Mexico, India, Russia and South Africa: the study on global AGEing and adult health (SAGE) wave 1. BMC Public Health 2015;15:88.

10 Arokiasamy P. India's escalating burden of non-communicable diseases. Lancet Glob Health 2018;6:e1262-3.

11 United Nations Population Fund. The state of World population 2011, 2011.

12 Marmamula S, Keeffe JE, Rao GN. Rapid assessment methods in eye care: an overview. Indian J Ophthalmol 2012;60:416-22.

13 Mactaggart I, Limburg $\mathrm{H}$, Bastawrous $\mathrm{A}$, et al. Rapid assessment of avoidable blindness: looking back, looking forward. Br J Ophthalmol 2019;103:1549-52.

14 Madans JH, Loeb ME, Altman BM. Measuring disability and monitoring the un convention on the rights of persons with disabilities: the work of the Washington group on disability statistics. BMC Public Health 2011;11:S4.

15 Groce NE, Mont D. Counting disability: emerging consensus on the Washington group questionnaire. Lancet Glob Health 2017:5:e649-50.

16 Marmamula S, Khanna RC, Yellapragada S, et al. Temporal trends in the prevalence and causes of visual impairment in the South Indian state of Telangana: a population-based cross-sectional study. BMJ Open 2019;9:e029114

17 Marmamula S, Challa R, Yellapragada S, et al. Temporal trends in the prevalence of spectacle use and spectacle coverage in India. Clin Exp Optom 2020;103:693-8.

18 Marmamula S, Sumalini R, Reddy TK. Prevalence of visual hallucinations. Clin Exp Optomet 2019.

19 Lamoureux EL, Fenwick E, Moore K, et al. Impact of the severity of distance and near-vision impairment on depression and visionspecific quality of life in older people living in residential care. Invest Ophthalmol Vis Sci 2009;50:4103-9.

20 Varma R, Wu J, Chong K, et al. Impact of severity and bilaterality of visual impairment on health-related quality of life. Ophthalmology 2006;113:1846-53.

21 Jacobs JM, Hammerman-Rozenberg R, Maaravi Y, et al. The impact of visual impairment on health, function and mortality. Aging Clin Exp Res 2005;17:281-6.

22 Chakrabarty D, Mandal PK, Manna N, et al. Functional disability and associated chronic conditions among geriatric populations in a rural community of India. Ghana Med J 2010;44:150-4.

23 Srinivasan K, Vaz M, Thomas T. Prevalence of health related disability among community dwelling urban elderly from middle socioeconomic strata in Bangaluru, India. Indian J Med Res 2010;131:515-21.

24 Nagarkar A, Kashikar Y. Predictors of functional disability with focus on activities of daily living: a community based follow-up study in older adults in India. Arch Gerontol Geriatr 2017:69:151-5.

25 Joshi K, Kumar R, Avasthi A. Morbidity profile and its relationship with disability and psychological distress among elderly people in Northern India. Int J Epidemiol 2003;32:978-87.

26 Gupta S, Yadav R, Malhotra AK. Assessment of physical disability using Barthel index among elderly of rural areas of district Jhansi (U.P), India. J Family Med Prim Care 2016;5:853.

27 Keshari P, Shankar H. Prevalence and spectrum of functional disability of urban elderly subjects: a community-based study from central India. J Family Community Med 2017;24:86.

28 Venkatorao T, Venkatarao T, Ezhil R, Jabbar S, et al. Prevalence of disability and handicaps in geriatric population in rural South India. Indian J Public Health 2005;49:11.

29 Onur I, Velamuri M. The gap between self-reported and objective measures of disease status in India. PLoS One 2018;13:e0202786.

30 WHO. International classification of functioning, disability and health. Geneva: ICF, 2001.

31 Borker S, Motghare D, Venugopalan P. Study of prevalence and types of disabilities at rural health centre Mandur-A community based cross sectional house to house study in rural Goa. 
32 Marella M, Busija L, Islam FMA, et al. Field-testing of the rapid assessment of disability questionnaire. 14, 2014.

33 Karmakar N, Datta A, Nag K, et al. Quality of life among geriatric population: a cross-sectional study in a rural area of Sepahijala District, Tripura. Indian J Public Health 2018;62:95-9.

34 Varma GR, Kusuma YS, Babu BV. Health-related quality of life of elderly living in the rural community and homes for the elderly in a district of India. Application of the short form 36 (SF-36) health survey questionnaire. Z Gerontol Geriatr 2010;43:259-63.

35 Ramadass S, Rai SK, Gupta SK, et al. Prevalence of disability and its association with sociodemographic factors and quality of life in India: a systematic review. J Family Med Prim Care 2018:7:1177-84.

36 Kuper H, Polack S, Limburg H. Rapid assessment of avoidable blindness. Community Eye Health 2006;19:68-9.

37 Marmamula S, Madala SR, Rao GN. Rapid assessment of visual impairment (RAVI) in marine fishing communities in South India-study protocol and main findings. BMC Ophthalmol 2011;11:26.

38 Marmamula S, Barrenakala NR, Challa R. Prevalence and risk factors for visual impairment among elderly residents in 'homes for the aged' in India: the Hyderabad Ocular Morbidity in Elderly Study (HOMES) Br J Ophthalmol 2020.

39 Marmamula S, Ravuri CSLV, Boon MY, et al. A cross-sectional study of visual impairment in elderly population in residential care in the South Indian state of Andhra Pradesh: a cross-sectional study. BMJ Open 2013;3 doi:10.1136/bmjopen-2013-002576

40 Gudlavalleti VSM. Challenges in accessing health care for people with disability in the South Asian context: a review. Int J Environ Res Public Health 2018;15:2366.

41 Rashmi MR, Kasthuri A, Rodrigues RJ. Senior friendly hospitals: development and application of criteria: a descriptive study. Indian J Community Med 2016;41:256-62.

42 Verma R, Khanna P. National program of health-care for the elderly in India: a hope for healthy ageing. Int $J$ Prev Med 2013;4:1103-7.

43 Lahariya C, Khandekar J, Pradhan SK. Effect of impairment and disability on health-related quality of life of elderly: a communitybased study from urban India. Indian J Community Med 2012;37:223.

44 Lahariya C. 'Ayushman Bharat' program and universal health coverage in India. Indian Pediatr 2018;55:495-506. 